\title{
OS PROFISSIONAIS DE ENFERMAGEM MERECEM MAIS QUE APLAUSOS
}

\author{
Verônica Egline Farias ${ }^{1}$ \\ http://orcid.org/0000-0002-5341-8836 \\ Geison Vasconcelos Lira ${ }^{1}$ \\ http://orcid.org/0000-0001-7623-0652
}

Objetivo: refletir acerca dos aplausos dirigidos aos profissionais de Enfermagem na "linha de frente" do combate à COVID-19. Método: artigo de opinião a partir das reportagens na mídia a respeito dos aplausos à Enfermagem, apesar da crescente precariedade de trabalho nos serviços públicos de saúde, nos últimos anos. Resultados: evidenciou-se a disparidade entre este gesto de gratidão, a escassez de recursos e carga de trabalho exaustiva, que tem se intensificado ainda mais neste contexto. Conclusão: Para além de apoio psicológico e social, é necessário também maior investimento na Saúde, para diminuir concretamente o risco de infecção que vem sendo enfrentado pelos profissionais devido à falta de recursos apropriados para seu trabalho.

Descritores: Enfermagem; Infecções por Coronavirus; COVID-19.

\section{NURSING PROFESSIONALS DESERVE MORE THAN APPLAUSE}

Objective: to reflect on the applause addressed to Nursing professionals on the "front line" of the fight against COVID-19. Method: opinion article based on media reports about applause for Nursing professionals, despite the growing precariousness of work in public health services in recent years. Results: the disparity between this gesture of gratitude, the scarcity of resources and an exhaustive workload became evident, which has intensified even more in this context. Conclusion: in addition to psychological and social support, greater investment in health is also needed to concretely reduce the risk of infection that professionals are facing due to the lack of appropriate resources for their work.

Descriptors: Nursing; Coronavirus infections; COVID-19.

\section{PROFESIONALES DE ENFERMERİA MERECEN MÁS QUE APLAUSOS}

Objetivo: reflexionar sobre los aplausos dirigidos a los profesionales de enfermería en la "primera línea" de la lucha contra COVID-19. Método: artículo de opinión desde los medios informativos sobre los aplausos para Enfermería, a pesar de la creciente precariedad del trabajo en los servicios de salud pública en los últimos años. Resultados: se hizo evidente la disparidad entre este gesto de gratitud, la escasez de recursos y una carga de trabajo exhaustiva, que se ha intensificado aún más en este contexto. Conclusión: además del apoyo psicológico y social, también se necesita una mayor inversión en Salud para reducir concretamente el riesgo de infección que enfrentan los profesionales debido a la falta de recursos apropiados para su trabajo.

Descriptores: Enfermería; Infecciones por Coronavirus; COVID-19

${ }^{1}$ Universidade Federal do Ceará (UFC), CE.

Autor Correspondente: Verônica Egline Faria. Email: veronica_eglinel7@hotmail.com

Recebido: 28/4/2020 - Aceito: 28/5/2020 


\section{INTRODUÇÃO}

Por muito tempo, a Enfermagem passou despercebida na sociedade. Raramente somos citados em jornais, revistas e noticiários diversos quando algo absurdo acomete nosso lado psicológico ou físico, e essa divulgação raramente acontece. Os estudos apontam que aproximadamente $90 \%$ dos profissionais de saúde já sofreram agressão física, psicológica ou assédio durante a jornada profissional $^{1}$. O contexto de trabalho desses profissionais é marcado por sofrimentos, mortes, ritmos de trabalho exaustivos e baixos salários, tendo agora como agravante dessa situação a pandemia por coronavírius ${ }^{(2)}$.

\section{DESENVOLVIMENTO}

Hoje o mundo para, diante da pandemia por COVID-19, para aplaudir e homenagear os trabalhadores de saúde, especialmente os da Enfermagem, considerada vulnerável por estar na linha de frente, por prestar assistência direta aos pacientes hospitalizados com a doença. Frente a essa circunstância, a sociedade os denominou heróis ${ }^{(1,2)}$. É apreciável essa terminologia, mas esquecem das condições do ofício desses profissionais no advento da política do neoliberalismo, que objetiva um enxugamento dos recursos materiais e humanos, como também a fragilização das condições no serviço(3)

Merecem aplausos, sim, quando conseguem improvisar diante de recursos reduzidos; merecem aplausos sim, quando saem correndo pelos corredores para salvar vidas, mas quando essa falta de recursos começa a atingir tanto os profissionais de saúde quanto os pacientes, apenas os aplausos serão suficientes?

Será que somente os aplausos e a denominação de "heróis" servirão para que possam salvar a si mesmos e aos doentes? Será que os aplausos heróicos trarão de volta nossos colegas de trabalho que contraíram COVID-19 e não sobreviveram? Segundo os dados do Conselho Federal de Enfermagem (Cofen), até o dia 06 de maio haviam sido registradas 88 mortes de profissionais de Enfermagem por COVID-19 no Brasil, sendo 40 mil o número em quarentena, contabilizando mais de 4,8 mil denúncias por falta de equipamentos de proteção individual adequado(4) ${ }^{(4)}$ presidente do Cofen afirmou em um pronunciamento que "Se nós não tratarmos dos recursos necessários para proteger os profissionais de saúde, vão faltar profissionais para atender a população"(4).

Será que os aplausos protegeriam a Enfermagem e a população contra a falta de profissionais, contra inconsistência dos recursos diante de um sistema de saúde próximo ao colapsado? Infelizmente, não. O que ainda nos mantém de pé é um sorriso, a alegria da cura estampada no rosto dos nossos pacientes, a alta após a internação, por exemplo. Mas, quando isso dispuser de uma frequência mínima, o que vai nos sustentar nessa guerra? O que nos motiva para continuar trabalhando nesse momento assombroso de mortes em larga escala e com qualidade de vida no trabatho quase zero? Ainda estamos aqui nessa batalha angustiante, motivados pela esperança de melhores condições de trabalho, de reconhecimento concreto da relevância da Enfermagem e de que tudo isso acabe logo. No entanto, o receio de contrairmos o vírus e ainda sermos considerados agente transmissor, colocando em risco quem amamos ao voltar para casa, aflige-nos todos os $\operatorname{dias}^{(4)}$

Cabe citar aqui a Medida Provisória no 927/2020(5), que visava alterar as relações trabalhistas permitindo o aumento da jornada de trabalho dos profissionais de saúde por até 24 horas, reduzindo o tempo de descanso para 12 horas e retirando a proteção trabalhista durante a pandemia por COVID-19, como cita no Artigo.3으 inciso VI "a suspensão de exigências administrativas em segurança e saúde no trabalho"(5). Vale ressaltar também a divulgação de cadastro para profissionais voluntários no combate ao coronavírus. Isso evidencia a influência real do neoliberalismo nas condições de trabalho do grupo em questão. Diante desses acontecimentos, o Cofen se manifestou contra, conseguindo a anulação de tal medida.

Ao fazer uma busca nas bibliotecas eletrônicas científicas online, nota-se um apanhado de estudos acerca do bem-estar, da satisfação e de melhores condições no trabalho em Enfermagem. Ainda assim, diante da atual realidade, isto parece insuficiente para sensibilizar os representantes políticos e as demais categorias gestoras, com relação os riscos laborais a que esses profissionais são expostos diariamente no ambiente de trabalho, com diversas precariedades

Em 9 de janeiro de 2020 a Organização Mundial da Saúde (OMS) iniciou uma campanha chamada "Nursing Now", em parceria com diversos órgãos representativos, declarando que seria o ano da Enfermagem. Diante desse posicionamento e do contexto epidemiológico atual que enfrentamos, faz-se necessário uma reflexão crítica de como estarão esses profissionais, no que se refere à saúde mental, física e ocupacional após a pandemia por coronavírus. É fundamental uma escuta qualificada para que se entendam todos os anseios e as lacunas que causam impasses na vida profissional desses trabalhadores e que, a partir disso, medidas de qualidade sejam providenciadas.

Essas medidas devem se interligar com o um número de casos suspeitos e confirmados por COVID-19 em 
ascensão exponencial no Brasil, de modo que haja uma gestão participativa nas unidades hospitalares. As condições de trabalho e o tempo de exposição à carga viral durante o manejo clínico da COVID-19 devem ser consideradas para que sejam alcançadas melhores condições no serviço, principalmente no que tange à escassez de Equipamento de Proteção Individual (EPI) aos profissionais de Enfermagem, por ser uma demanda a nível nacional neste periodo de pandemia.

É relevante destacar o papel dos gestores das unidades hospitalares de referência e, em especial, dos coordenadores das equipes de Enfermagem, para que possam elaborar um fluxo de escala, ofertar capacitações de manejo clínico do coronavírus e viabilizar a distribuição de EPI aos profissionais de Enfermagem envolvidos na assistência aos pacientes com COVID-19 conforme as recomendações do Ministério da Saúde. Com relação ao fluxo de escala, poderíamos citar, o rodízio, com o objetivo de diminuir o tempo de exposição dos profissionais ao vírus, no entanto para que isso se efetive, é essencial um número maior de profissionais em cada equipe, o que refletiria no aumento das contratações temporárias.

Apesar da complexidade em prever os impactos dessa pandemia, muitas unidades despreparadas para atuar diante de uma curva em crescimento exponencial acabam por comprometer os profissionais de Saúde, pela falta dos insumos e de capacitações quanto ao uso correto desses equipamentos. Como foi citado anteriormente, as denúncias exorbitantes por falta de EPI evidenciam o quanto a Enfermagem está vulnerável durante as práticas assistenciais.

\section{CONSIDERAÇÕES FINAIS}

Os heróis geralmente ganham aplausos, estátuas ou medalhas, mas nós, enfermeiros e demais profissionais da Enfermagem, só queremos melhores condições de trabalho, salários dignos que não nos obriguem a depender de vários vínculos laborais frágeis e exaustivos. A Enfermagem trava uma luta árdua por melhores condições de trabalho, podemos citar dentre elas, a jornada de trabalho e o piso salarial que infelizmente ainda não são definidos a nível nacional. É preciso aproveitar esse momento para demonstrar o verdadeiro valor dos profissionais de Enfermagem, sem reduzi-lo a uma crise sanitária, mas reafirmando que estes são necessários a longo prazo, dentro do Sistema de Saúde brasileiro.

Será que a sociedade continuará a nos aplaudir? Será que os governantes farão algo para viabilizar qualidade de vida e de trabalho para profissionais da Enfermagem? Está na hora de juntarmos forças e mostrarmos o quanto somos protagonistas do cuidado ao usuário, defendendo que melhores condições de trabalho são um fator primordial para aprimorar a assistência em Saúde.

Lutem pela Enfermagem, assim como lutam pela vida. A Enfermagem é quem segura a mão, quem dança, quem tenta arrancar sorrisos, quem constrói um ambiente de cura, num momento em que os pacientes isolados veem esses profissionais como parte da família e tudo isso é feito dentro de um ambiente escasso de recursos. A Ciência necessita de um longo período para desenvolver uma cura à COVID-19. Enquanto isso, a Enfermagem continua no campo de batalha, a espera de melhorias.

\section{REFERÊNCIAS}

1. Passos L, Prazeres F. A Mão que Agrediu Agora Aplaude: A Imagem dos Profissionais de Saúde Frente à Pandemia COVID-19. Gazeta Médica, 2020 abr [acesso em 14 abr. 2020]. Disponivel em: https://www.researchgate.net/publication/340686564_A_Mao_ que_Agrediu_Agora_Aplaude_A_Imagem_dos_Profissionais_ de_Saude_Frente_a_Pandemia_COVID-19

2. Fulton JS. This spring is different. Clinical Nurse Specialist: 2020 May/June [acesso em 28 abr. 2020]; 34(3), p. 92. Disponivel em: https://journals.lww.com/cns-journal/FullText/2020/05000/This_Spring_Is_Different.2.aspx

3. Souza MMT, Passos JP, Tavares CMM. Sofrimento e precarização do trabalho em enfermagem. Revista de Pesquisa Cuidado é Fundamental Online, 2015 [acesso em 28 abr. 2020]; 7(1). Disponivel em: https://www.researchgate.net/publication/273163097_ Suffering_and_precariousness_at_work_in_nursing
4. Oliveira E. Brasil tem 30 mortes na Enfermagem por COVID-19 e 4 mil profissionais afastados. Gl, São Paulo, 2020 abr. 17 [acesso em 04 mai. 2020]. Disponivel em: https://gl.globo. com/bemestar/coronavirus/noticia/2020/04/17/brasil-tem-30-mortes-de-profissionais-de-enfermagem-por-coronavirus-e-mais-de-4-mil-afastados-pela-doenca.ghtml

5. Presidência da República. Secretaria Geral. Medida Provisória № 927, de 22 de março de 2020. Dispõe sobre as medidas trabalhistas para enfrentamento do estado de calamidade pública reconhecido pelo Decreto Legislativo nㅇ 6, de 20 de março de 2020, e da emergência de saúde pública de importância internacional decorrente do coronavirus (COVID-19), e dá outras providências. Brasília (DF); 2020 mar. [acesso em 22 mai. 2020]. Disponivel em: http://www.planalto.gov.br/ccivil_03/_ato2019-2022/2020/Mpv/mpv927.htm 